\title{
PHOTOGRAMMETRIC STUDY OF THE QUBBET EL-HAWA COPTIC CHURCH (ASWAN, EGYPT)
}

\author{
A. T. Mozas-Calvache ${ }^{1 *}$, J. L. Pérez-García ${ }^{1}$, V. Barba-Colmenero ${ }^{2}$, A. Jiménez-Serrano ${ }^{2}$ \\ ${ }^{1}$ Dept. Ingeniería Cartográfica, Geodésica y Fotogrametría, University of Jaén, 23071 Jaén, Spain - (antmozas, jlperez)@ujaen.es \\ ${ }^{2}$ Dept. Antropología, Geografía e Historia, University of Jaén, 23071 Jaén, Spain - vicente@arq13.net, ajiserra@ujaen.es
}

Commission II, WG II/8

KEY WORDS: Photogrammetry, 3D model, orthoimages, Coptic Church

\begin{abstract}
:
This paper presents the method applied and the results obtained in the photogrammetric study of the Qubbet el-Hawa Coptic Church. After several archaeological interventions, the ruins of this church were completely uncovered of sand. Therefore, a geometric documentation is justified in prevision of possible damages or deterioration that could affect it, considering the weakened status of several structures. In this context, we selected close-range photogrammetry because of the site conditions which include several vertical walls and occlusions that complicated the use of other terrestrial methods. In addition, a real texture of the object was demanded in order to obtain a complete documentation of the church. In this sense, some decorations and wall paintings were still visible causing this requisite of documentation based on real textures. However, the use of terrestrial photogrammetry was complicated due to the presence of occlusions, and in addition the use of Remotely Piloted Aircraft Systems (RPAS) was not allowed. So a method using a mast of about 4 to 6 metres was considered in order to lift the camera, avoiding these obstacles and reducing the amount of photographs needed. Applying this method, a great set of photographs was acquired and the scene covered with convergent images. The results of the photogrammetric processes were several metric products such as a 3D model with real textures, a ground Digital Elevation Model (DEM), several orthoimages, sections, etc. In addition a preliminary virtual reconstruction of the church has been developed based on these results. In conclusion, we have obtained a complete and reliable geometric documentation of the site and other derived products that can be used for other purposes. The method used has demonstrated its efficiency in these types of studies.
\end{abstract}

\section{INTRODUCTION}

Photogrammetry applied to heritage documentation has undergone a great development in the latest decades due to the appearance of new acquisition sensors, platforms and computing algorithms. We firstly highlight the development and application of new sensors such as low-cost non-metric cameras (Ogleby et al., 1999; Celikoyan, 2003; Cardenal et al., 2004; Chandler et al., 2005; Covas et al., 2015; Fiorillo et al., 2016; Barazzetti, 2017a and 2017b). Second, the use of new platforms, such as Remotely Piloted Aircraft Systems (RPAS) (Colomina and Molina, 2014; Nex and Remondino, 2014; Campana, 2017), which allow us to lift sensors several metres over the ground and obtain photographs from higher points of view with respect to terrestrial photogrammetry. This supposes an enormous advantage for documentation in contrast to traditional terrestrial techniques where image acquisition from elevated locations was almost impossible in most cases. Third, we also must highlight the implementation in commercial software applications of several algorithms that has eased the photogrammetric processes from the acquisition and orientation of photographs to the obtaining of point clouds. This is the case with the Structure from Motion algorithm (SfM) (Ullman, 1979; Koenderink and Van Doorn, 1991; Lowe, 2004; Szeliski, 2010) and the dense MultiView Stereo 3D reconstruction algorithms (MVS) (Scharstein and Szeliski, 2002; Seitz et al., 2006; Szeliski, 2010; Furukawa and Hernández, 2015).

Despite the current possibilities of using RPAS, there are some cases where the use of these techniques is not available or presents difficulties. In these cases, it is justified to use other acquisition platforms such as masts, balloons, etc. (Bitelli et al., 2003; Altan et al., 2004; Mozas et al., 2012a; Mozas et al., 2012,; Verhoeven et al., 2012; Martínez et al., 2013; Ortiz et al., 2013;
Pérez et al., 2018). This was the case described in this paper, which consisted of the photogrammetric study of the Coptic Church ruins located in the Qubbet el-Hawa archaeological site in Aswan (Egypt) (Figure 1). In this case the authorities did not allow us the use of RPAS, causing the selection of alternative image acquisition methods from high points of view.

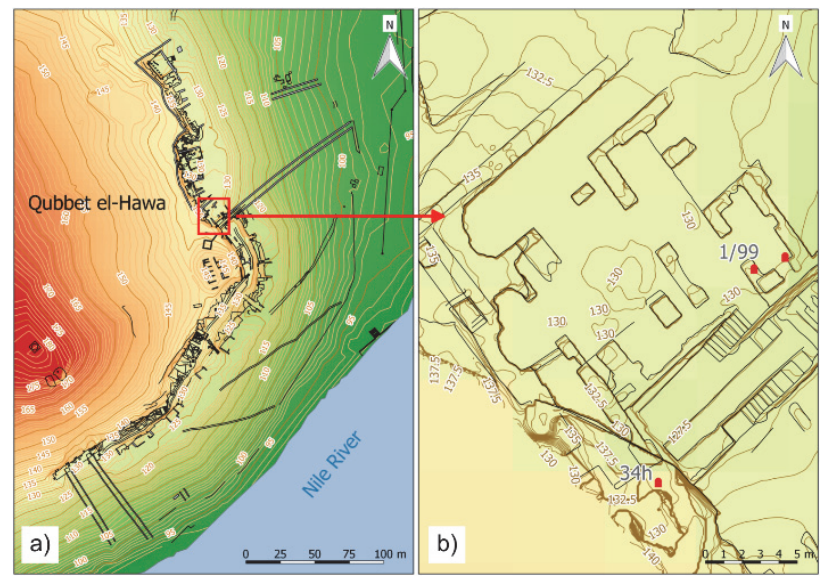

Figure 1. Location of the Qubbet el-Hawa Coptic Church ruins: a) General view of the Qubbet el-Hawa archaeological site and location of the church; b) plan view of the Coptic Church ruins.

The Qubbet el-Hawa Coptic Church is located in the middle of a hill, which is elevated about 100 metres above the Nile River on its west bank, just opposite to the Aswan urban area. The church extends over an area of about $270 \mathrm{~m}^{2}$. The construction of the church took advantage of the hillside. Thus, the southwest part was excavated in the rock of the hill taking advantage of previous

* Corresponding author 
excavations and the structures of some ancient tombs. The ruins are composed of several walls, which have remained higher toward the hill and lower toward the outside (Figure 2). In this zone, there are some ruins of vaults and a partially-demolished apse (Figure 2d).

Considering these premises, the main goals of this study were the obtaining of a 3D model of the status of the ruins in order to document the church in general and other photogrammetric products and analyse in more detail some specific elements such as the apse and some walls. As examples, a 3D model of the ruins and several orthoimages of the ground and other elements were demanded. A determinant factor in method selection was that the 3D model required must contain real textures. In addition, other secondary goals were considered, such as the determination of a virtual reconstruction of the church based on the metric products obtained in this study, analyses described by other authors and other information extracted from contemporary Coptic churches of the region.

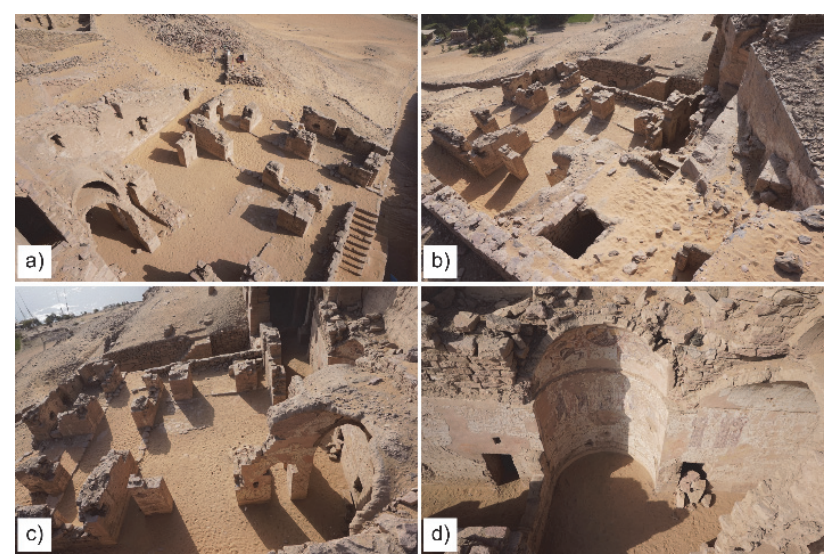

Figure 2. Views of the Qubbet el-Hawa Coptic Church ruins: a) north part; b) southeast part; c) south part; d) apse view.

\subsection{Historic context of the Qubbet el-Hawa Coptic Church}

The Qubbet el-Hawa archaeological site presents an archaeological sequence that covers from the $6^{\text {th }}$ Dynasty to the medieval period. Among others, we must highlight remains of a large necropolis comprising a great amount of rock-hewn tombs dated to several periods of ancient Egypt (from the $6^{\text {th }}$ Dynasty to the New Kingdom). During the last decades of the Late Period (around the end of the $5^{\text {th }}$ century $\mathrm{BC}$ ) it seems that the necropolis was abandoned until the $6^{\text {th }}$ century $\mathrm{AD}$, when the hill was reused again. In this case, a Coptic community of monks occupied at first some earlier Egyptian tombs (hermit monasticism), which were later extended with the construction of other buildings, eventually becoming a monastery with its church.

The monastery is located at a higher position with respect to the situation of the main tombs. Unfortunately, there is not much information about this Coptic archaeological site and its configuration. As an example, several authors described that the monastery depended on the adjacent monastery of Dayr Anba Hadra (wrongly known as St. Simeon). In 1998, the Supreme Council of Antiquities of Egypt (SCA) decided to move away the sand located at the northern area of the Khunes' tomb (QH34h). Several ruins of a church appeared in this zone although authors such as Grossmann (1985) had previously documented their presence. The church was configured taking advantage of some previous burial structures (e.g. QH34h tomb) and the slope of the hill. In this sense, a great part of the church is excavated in the hillside. During this process some decorations, mural paintings and several Coptic, Arabian and Greek texts were discovered mainly on an apse, and the adjacent walls located in the southwest part of the church (Figure 2d). Subsequently, in 2010, there were other works promoted by the SCA that consisted of moving away the remaining sand layers. These works allowed us to obtain a complete vision of the church ruins. Recently, several studies have shown different analyses of the architecture of the church (Conquin and Martin, 1991; Grossmann, 1991, Dekker, 2008; Dekker, 2013), including the hypothesis of the existence of two churches merged by several building elements (Dekker, 2008; Middelton-Jones, 2013). We also can highlight studies of the decoration and inscriptions of the church (decorations and painting walls) such as those described by Dekker (2008) and Dekker (2013).

The Qubbet el-Hawa archaeological site has been excavated and studied since the late $19^{\text {th }}$ century. As an example, we can highlight studies such as those carried out by Elmar Edel (from 1957 to 1984). More recently, the University of Jaén (Spain) has developed ten field campaigns (2008-2018) in order to study and excavate several tombs. These works have included the generation of a 3D model of the necropolis (Pérez et al., 2018). In this context, this photogrammetric study of the Coptic Church has been developed.

\section{METHOD AND APPLICATION}

The method selected in order to achieve the goals previously described were based on close-range photogrammetry due to the reduced dimensions of the zone and the requirement of real textures. Moreover, other techniques such as Terrestrial Laser Scanning (TLS) were not available at the moment of data acquisition. In addition, the current status of the object, which includes a large amount of medium-height walls (about 2 metres) (see Figure 2c) suggested the use of photogrammetry instead of TLS because the number of scanner stations could be increased to cover the complete scene. In contrast, close-range photogrammetry could reduce data acquisition by lifting cameras some metres over the ground, avoiding the presence of obstacles. Thus, the selection of the technique was greatly conditioned by the status of the object and the availability of instruments. However, another issue appeared regarding lifting the camera. The use of RPAS was not allowed in this study. Consequently, an acquisition procedure based on a mast was developed in order to guarantee the complete coverage of the elevated zones of the object and avoid occlusions.

Waldhäusl and Ogleby (1994) and Waldhäusl et al. (2013) described the recommendations of the International Committee of Architectural Photogrammetry (CIPA) for architectural photogrammetric projects planning using non-metric cameras (known as $3 \times 3$ rules). In the geometric rules section, CIPA recommended multiple photographic all-around coverage that includes taking a ring of images all around the object, overlapping each other by more than $50 \%$, and taking normal stereoscopic images for 3D restitution. Therefore, the acquisition of photographs must consider these rules. In this context, we selected the method described by Pérez-García et al. (2018) for documenting the Qubbet el-Hawa archaeological site that consisted of the use of a low-weight mast of 4 and 6 metres managed by two operators with a camera mounted and tilted at $45^{\circ}$. The image acquisition was developed from several stations of the mast, obtaining eight photographs from each station covering $360^{\circ}$ (by turning the system $45^{\circ}$ for each photograph) (Figure 3a, Figure $3 \mathrm{~b}$ and Figure 3c). To cover the full zone, several stations of the mast were distributed over the study area considering the presence of occlusions in order to establish the distance between stations and the mast height. The main goal was to achieve a full coverage of the object from several convergent photographs. This convergence was obtained from several 
photographs obtained from several stations located close to the object (Figure 3d). The camera shutter and the framing were controlled remotely.
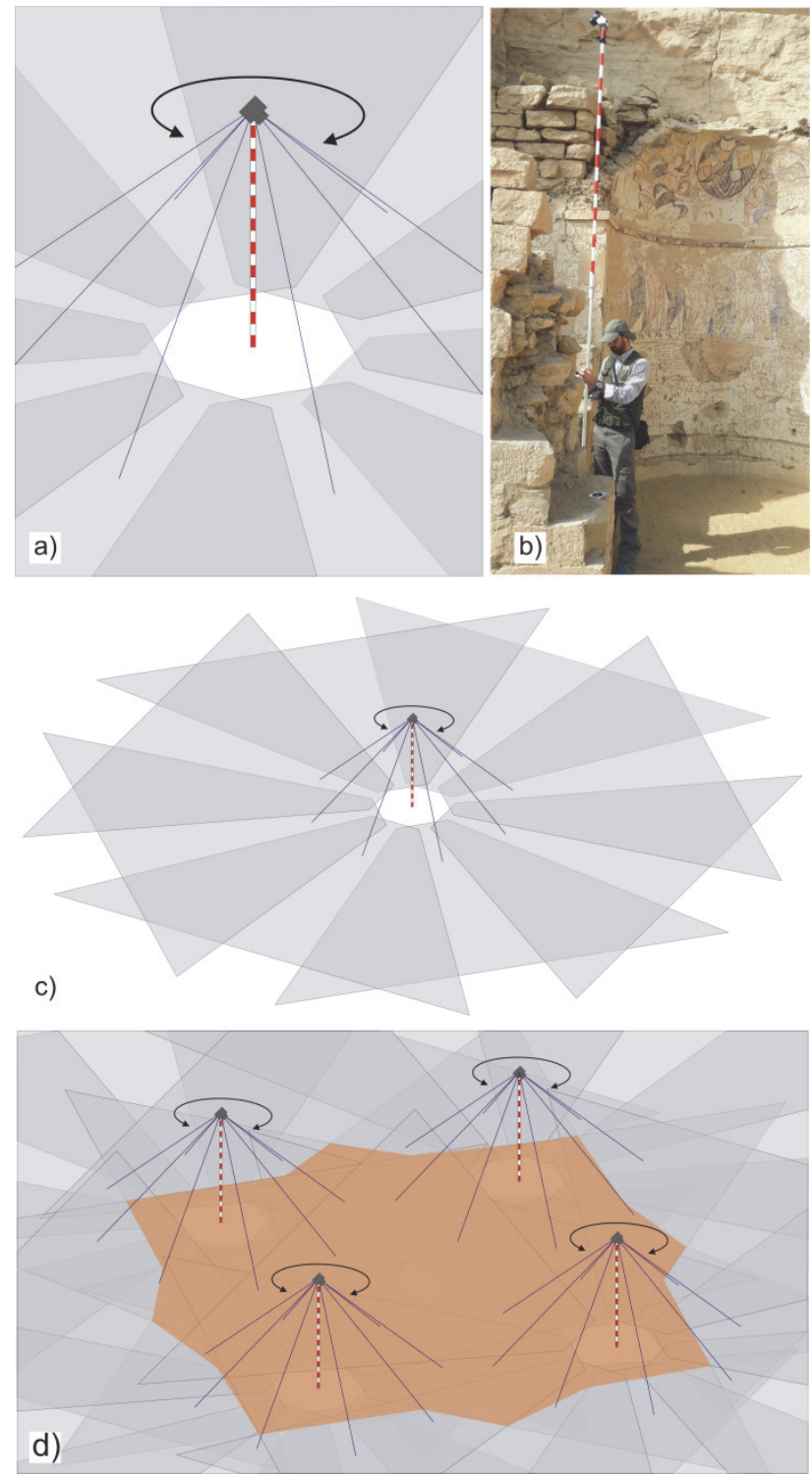

Figure 3. Acquisition of photographs using a mast based on

Pérez et al. (2018): a) detailed view of the system; b) example of image acquisition developed in this study; c) schema of an individual mast station acquiring eight photographs by turning the system $45^{\circ}$ horizontally between shots, using a camera (focal length $24 \mathrm{~mm}$ ) tilted $45^{\circ}$ and a mast height of 4 metres; d) example of four mast stations and zone covered with several

convergent photographs (area displayed in orange).

Considering these premises, in this study we densified the number of stations of the mast with respect to that executed by Pérez et al. (2018) because of the great presence of walls in the scene. We tried to avoid the occlusions caused by these walls. Therefore, the distance between stations was reduced considerably. In this sense, the image coverage was checked using the remote viewer. We selected 6 metres of height in all stations located on the ground of the church and 4 metres in the stations located on the higher parts of the church (southwest area) (Figure $3 b$ ). These zones were accessible because the hill slope allowed access to these zones (see photographs in Figure 2). We used a Sony a5000 camera with a focal length of $16 \mathrm{~mm}$ (lens equivalent to a $24 \mathrm{~mm}$ on a full frame sensor). These camera parameters suppose $240 \mathrm{~m}^{2}$ and $106.6 \mathrm{~m}^{2}$ of photograph coverage (on a flat terrain) using a mast height of 4 and 6 metres respectively and $45^{\circ}$ of camera inclination (see parameters for several heights, focal lengths and camera tilts in Pérez et al., 2018). Definitely, two operators carried out the acquisition of photographs, one supported the mast and another controlled the camera and checked framing by using the Wi-Fi remote control. Several stations of the mast were distributed (by strips) in order to cover the full scene, including an external security margin. After the acquisition stage, a visual check of image coverages was carried out controlling the correct acquisition of photographs.
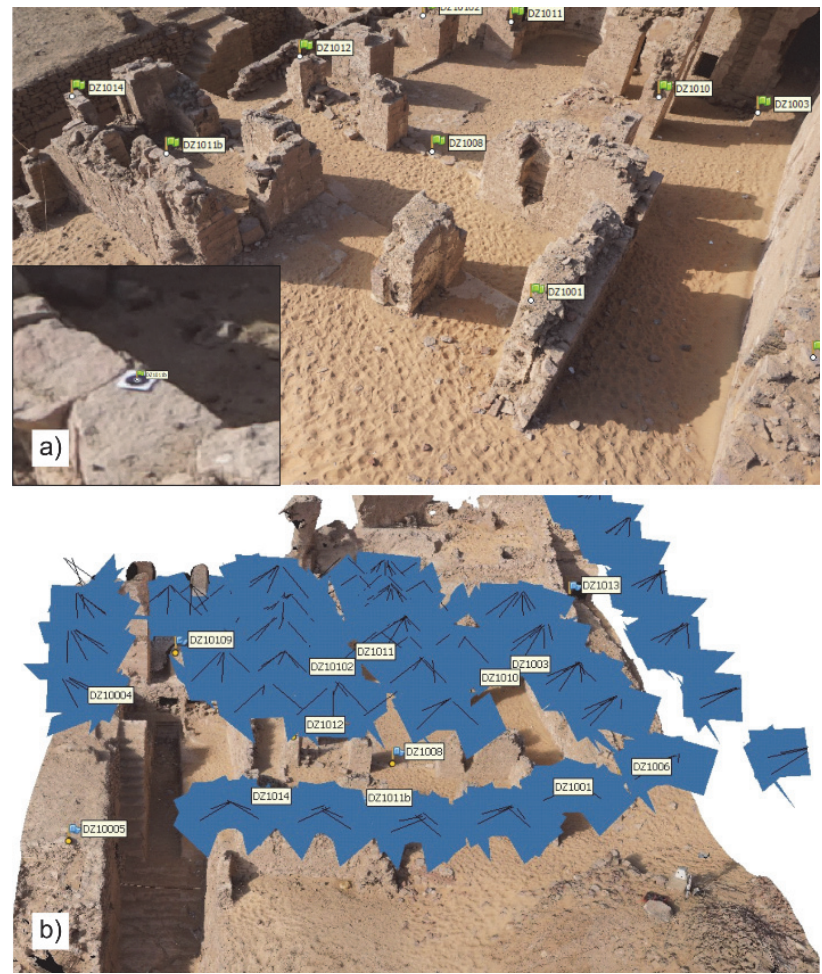

Figure 4. a) View of targets distribution over the scene; b) view of photograph distribution obtained after the orientation stage using PhotoScan.

In addition to the image acquisition using a mast, we also developed a terrestrial image acquisition of some specific elements of interest such as the apse and some walls that delimited the church. Around 214 photographs were obtained from the mast and 55 from the ground.

The field works were completed with the distribution of some targets over the scene in order to facilitate the photograph orientation procedure. These targets were surveyed using a total station that obtained 3D coordinates referred to a global system determined by using several common points previously measured using GNSS. More specifically, we used the EPSG:32636 reference system (WGS84 and projection UTM 36N) and heights referred to the local reference of the archaeological site. In total, we used 26 targets for both the mast and the terrestrial survey (Figure 4a). We have to note that all targets were measured from one station using distance measurement without a reflector (accuracy of $2 \mathrm{~mm}+2 \mathrm{ppm}$ ). In the case of cartographic products, the coordinates were transformed to the projected reference system (EPSG:32636). The correction consisted of the application of the local scale factor to the XY coordinates $(\mathrm{k}=$ 0.9996). 


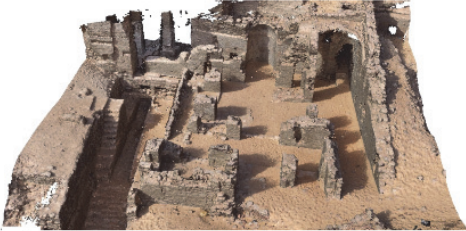

a)

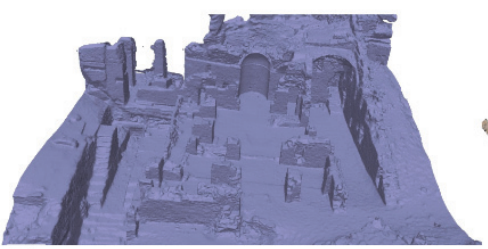

b)

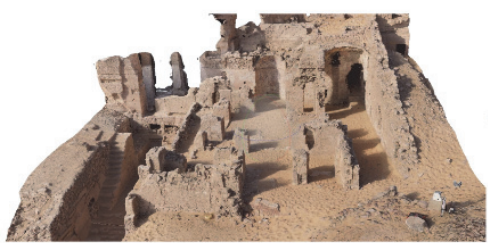

c)

Figure 5. Examples of the photogrammetric process performed using PhotoScan: a) point cloud; b) 3D mesh; c) 3D model with real texture; d) ground DEM; e) ground orthoimage; f) contour lines.

The office work included the orientation of photographs (Figure $4 \mathrm{~b}$ ), the obtaining of the 3D point cloud (Figure 5a), the 3D mesh (Figure 5b) and a 3D model with real texture (Figure 5c) and several Digital Elevation Models (DEMs) (ground DEM in Figure 5d) and other derived products, such as orthoimages (ground orthoimage in Figure 5e) and contour lines (Figure 5f). These tasks were performed using Agisoft PhotoScan and Bentley ContextCapture software. Other products were obtained derived from the photogrammetric process such as sections, digitizing of elements, etc. As a result of the orientation stage, a Root Mean Square Error (RMSE) of about 3 millimetres was obtained both for control points and check points.

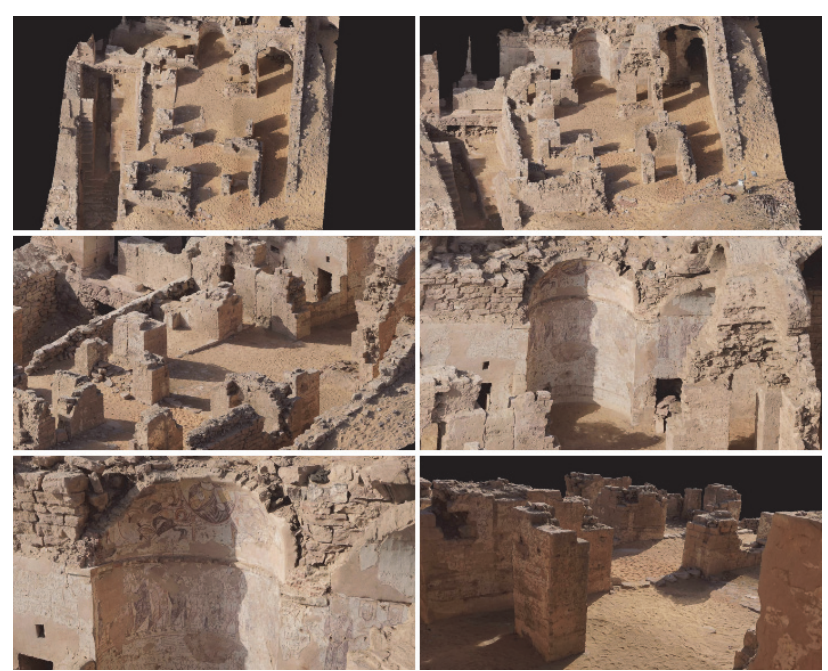

Figure 6. Views of the 3D model of the Coptic Church.

The virtual reconstruction was carried out using as a basis those elements of the church structure digitized from the 3D model, the ground orthoimage and some sections determined from the 3D model. However, the ruins' status with several missed structures made this reconstruction difficult. In addition, we also used several plans published by several authors, such as that described by Dekker (2013). This preliminary reconstruction was developed using AutoDesk 3ds Max software.
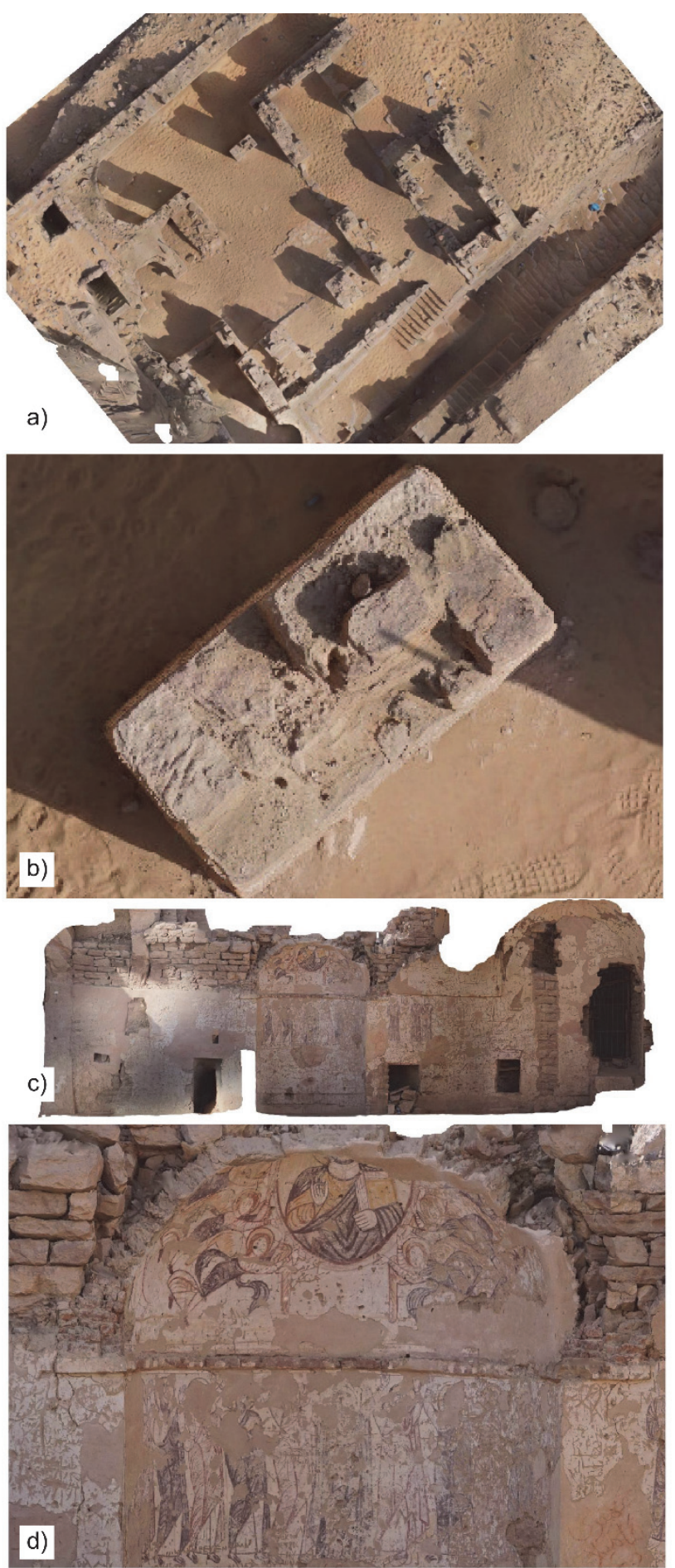

Figure 7. Orthoimages obtained: a) ground orthoimage; b) detailed view of ground orthoimage; c) SW wall; d) detailed view of SW wall orthoimage. 


\section{RESULTS}

As results of the photogrammetric procedures, we obtained several products such as a $3 \mathrm{D}$ model of the church ruins containing real photograph textures (Figure 6). This 3D model contains more than 2.2 million faces. Obtaining this product has a great importance in the documentation of this church and in supporting works undertaken by other researchers such as archaeologists, historians, architects, etc. In this sense, a reduced version of the 3D model has been shared on the Internet using the Sketchfab platform (https://skfb.ly/6LAzn). Secondly, we also used the 3D model to obtain sections and measures that allowed us to perform other tasks such as the virtual reconstruction of the church.
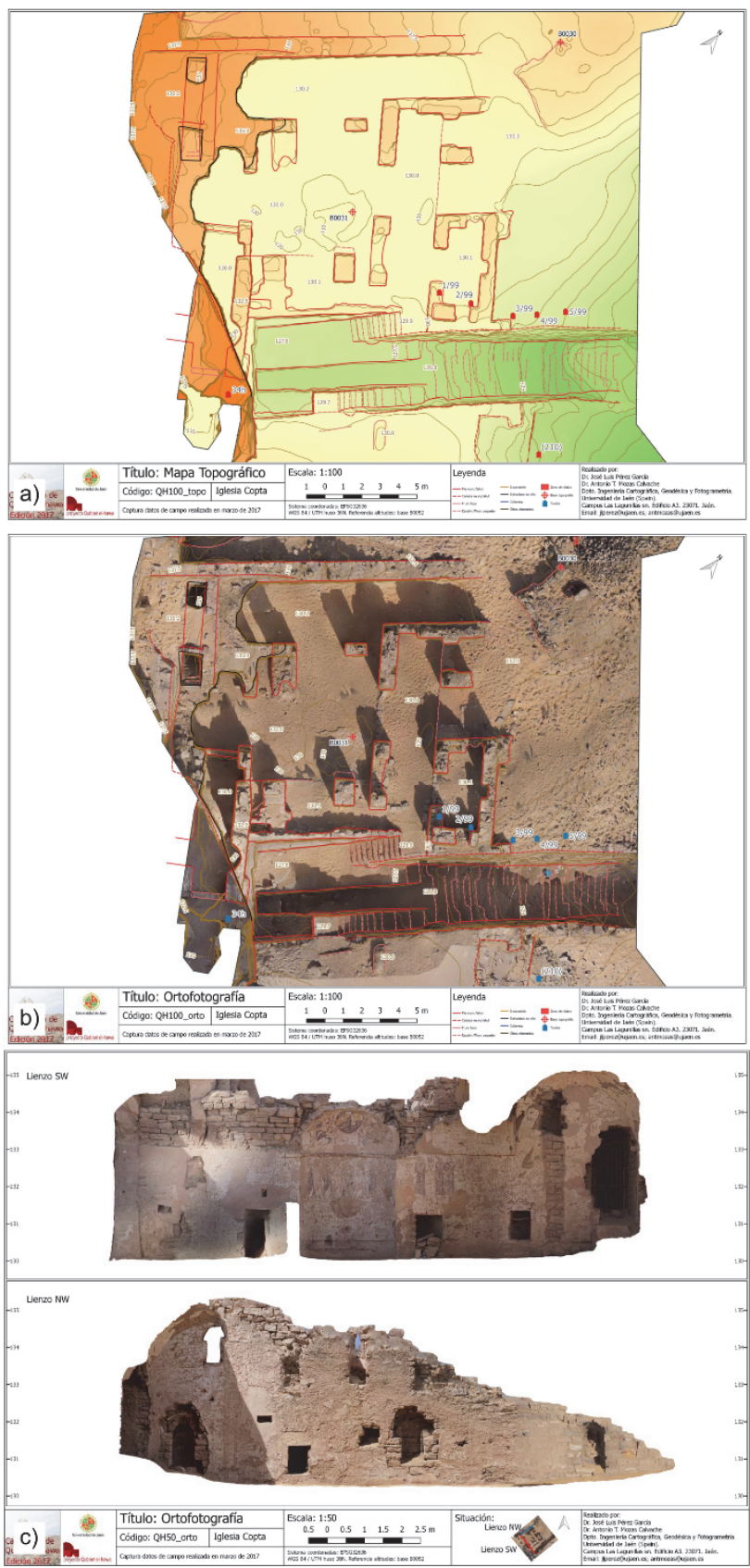

Figure 8. Maps of the Qubbet el-Hawa Coptic Church at scale 1:100: a) Topographic map; b) ground orthoimage map; c) SW and NW walls orthoimage map.
Based on the photogrammetric products previously determined, we also obtained a ground DEM with a resolution of one centimetre and several orthoimages and contour lines. The ground orthoimage is considered the main cartographic documentation of the church. This ground orthoimage had a resolution of five millimetres (Figure 7a). Additionally, we generated a topographic map (Figure 8a) and an orthoimage map (Figure 8b) at scale 1:100 using the contour lines obtained from the DEM and the ground orthoimage. We also included some elements of interest digitized using both the orthoimage and the DEM as basis. Independently, two orthoimages of the main remaining walls (Southwest and Northwest) of the church were obtained with a resolution of two millimetres (Figure 7b). These products were represented in an orthoimage map at scale 1:50 (Figure 8c).
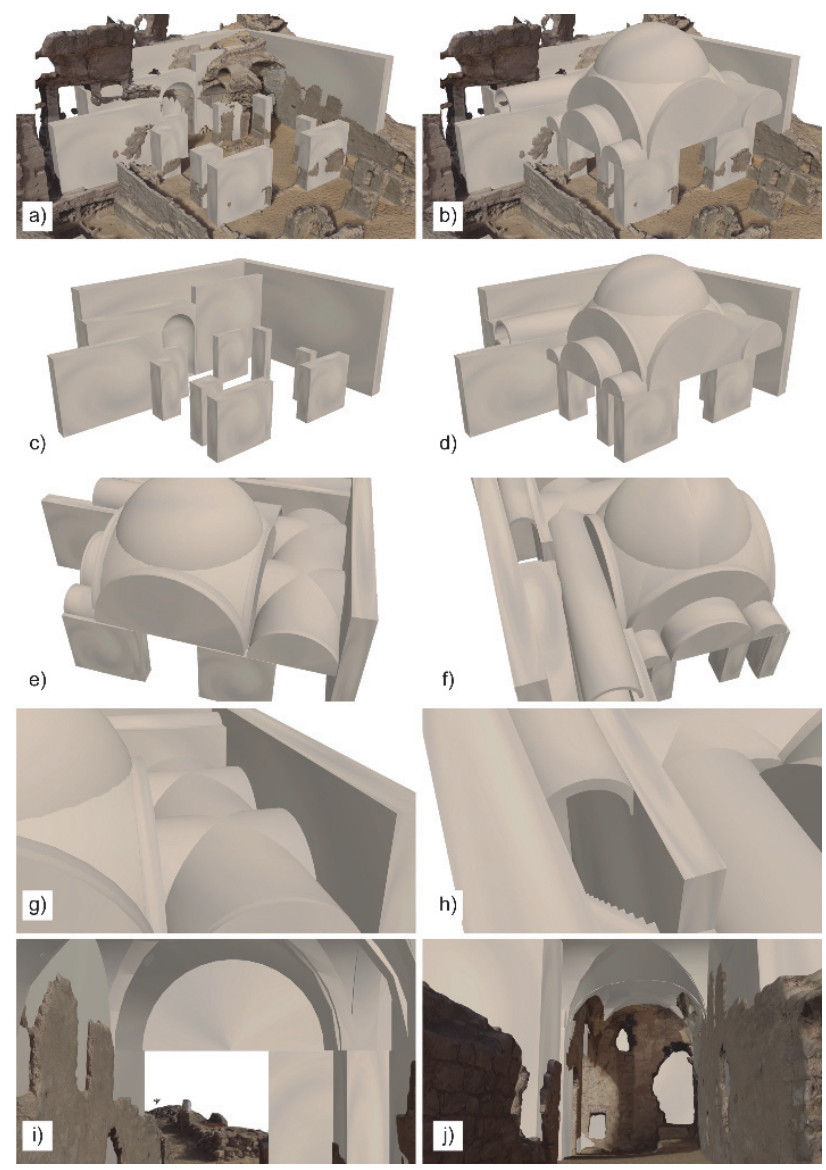

Figure 9. Preliminary virtual reconstruction of the Coptic Church: a) view of walls and 3D model; b) view of the church and 3D model; c) view of walls; d) view of the church; e) detailed view from east; f) detailed view from south; g) detailed view of the vaults; h) detailed view of stairs; i) and $j$ ) interior views of the vaults.

Finally, we obtained a preliminary virtual reconstruction of the church (Figure 9). Our main hypothesis, which coincides with that described by several authors, is that the church contained a main dome in the middle. This central dome was also described in close Coptic Churches, such as Dayr Anba Hadra (St. Simeon) (Gabra, 2010). In addition, several vaults and apses are included. However, the current status of the different structures and the disappearance of others elements mean that this virtual reconstruction must be considered as preliminary, waiting for forthcoming studies that analyse other aspects such as the construction phases, materials, etc. 
Another study carried out using these cartographic products is related to the orientation of the church. This orientation was calculated from its main axis after digitizing several points that defined it. More specifically, the axis was obtained from the ground orthoimage and was transformed from the project reference system (EPSG:32636) to the WGS84 system without projection (EPSG:4326, longitude and latitude). The final azimuth obtained was about $48^{\circ} 57^{\prime} 36^{\prime \prime}$, outside the solar sunrise arc. This supposes the most northern orientation with respect to those Aswan churches analysed by Dallas (2019). We have not been able to establish relationships between this orientation with respect to other possible references (e.g. stars or planets' rise, Nile river course, etc.). In this sense, our assumption is that the orientation of the church was mainly conditioned by the geological and topographical conditions of the hill and the previous structures of tombs.

\section{CONCLUSIONS}

In this paper, we have described the method developed and the results obtained from the photogrammetric study of the Qubbet el-Hawa Coptic Church. It represents the first documentation of this type carried out until this moment of this important site. The documentation obtained is very important considering that since the last excavations carried out in 2010 several elements, such as the wall paintings, have been damaged intentionally. In this sense, we highlight the importance of this photogrammetric study that has allowed us to obtain several metric products with real images and share them with the scientific community, generating reliable products describing the current status of the church. In this sense, the main goal of this study which consisted of obtaining a metric documentation of the site has been achieved easily. More specifically, we have obtained a complete 3D model with real textures, several orthoimages, sections, DEMs, etc.

The acquisition method selected was conditioned by the characteristics of the scene (presence of occlusions caused by walls). Despite the impossibility of using RPAS to lift the camera, the use of the mast jointly with the acquisition procedure using eight photographs from each station have demonstrated its efficiency in developing these types of studies.

We also have to note that all products have been referred to a global reference system. This aspect eases the interpretation of these results and their possible inclusion in future studies. In addition, we must also highlight the obtaining of new cartographic products of this site such as a plan of the church including a topographic map, additional orthoimages of the SW and NW walls, sections, etc. These products have allowed us to undertake a preliminary virtual reconstruction of the church that can be used as a basis for forthcoming studies in order to define its structure and other purposes such as educational applications. Future work will focus on the relationships of this structure with the surrounding tombs. We can also analyse how the previous structures and the topography of the terrain conditioned the construction of the church. In this sense, the study of other contemporary churches located in the Aswan region could be of interest. From a geomatic point of view, we will study the monastery located on a higher level of the hill and the QH34h tomb that is located jointly to the church.

\section{ACKNOWLEDGEMENTS}

The present paper is the result of research carried out with funds provided by the MINECO (Government of Spain) as part of the project HAR2016-75533-P "Excavación, estudio histórico y conservación de las tumbas del Reino Medio de la necrópolis de Qubbet el-Hawa (Asuán, Egipto)".

\section{REFERENCES}

Altan, M.O., Celikoyan, T.M., Kemper, G., Toz, G., 2004. Balloon photogrammetry for cultural heritage. Int. Arch. Photogramm. Remote Sens. Spatial Inf. Sci., XXXV-B5, 964968.

Bitelli, G., Tini, M.A., Vittuari, L., 2003. Low-height aerial photogrammetry for archaelogical orthoimaging production. Int. Arch. Photogramm. Remote Sens. Spatial Inf. Sci., XXXIV5/W12, 55-59.

Barazzetti, L., Previtali, M., Roncoroni, F., 2017a. 3D Modelling with the Samsung Gear 360. Int. Arch. Photogramm. Remote Sens. Spatial Inf. Sci., XLII-2-W3, 85-90.

Barazzetti, L., Previtali, M., Roncoroni, F., 2017b. Fisheye lenses for 3D modeling: evaluations and considerations. Int. Arch. Photogramm. Remote Sens. Spatial Inf. Sci., XLII-2/W3, 79-84.

Campana, S., 2017. Drones in Archaeology. State-of-the-art and Future Perspectives. Archaeol. Prospect., 24(4), 275-296.

Cardenal, J., Mata, E., Castro, P., Delgado, J., Hernandez, M. A., Pérez, J. L., Ramos, M., Torres, M., 2004. Evaluation of a digital non metric camera (Canon D30) for the photogrammetric recording of historical buildings. Int. Arch. Photogramm. Remote Sens. Spatial Inf. Sci., XXXV-B5, 564-569.

Celikoyan, T.M., Altan, M.O., Kemper, G., Toz, G., 2003. Calibrating and using an olympus camera for balloon photogrammetry. In Proc. XIXth International Syposium-CIPA 2003, Antalya, Turkey, 380-382.

Chandler, J.H., Fryer, J.G., Jack, A., 2005. Metric capabilities of low-cost digital cameras for close range surface measurement. Photogramm. Rec., 20(109), 12-26.

Colomina, I., Molina, P., 2014. Unmanned aerial systems for photogrammetry and remote sensing: A review ISPRS $J$. Photogramm., 92, 79-97.

Coquin, R.G., Martin, S.J., 1991. Dayr Anba Hadra: History. In The Coptic Encyclopedia (CE), 3, Macmillan Press, New York ,744-745.

Covas, J., Ferreira, V., Mateus, L., 2015. 3D reconstruction with fisheye images strategies to survey complex heritage buildings. In Digital Heritage 2015.,IEEE, Granada, Spain, 123-126.

Dallas, T. G., 2019. On the Orientation of Coptic Churches in Egypt. In Environment and Religion in Ancient and Coptic Egypt: Sencing the Cosmos through the eyes of the Divine. Archaeopress. In press.

Dekker, R., 2008. New discoveries at Dayr Qubbat al-Hawâ, Aswan: architecture, wall paintings and dates. Eastern Christian Art ECA, 5, 19-36.

Dekker, R., 2013. An Updated Plan of the Church at Dayr Qubbat al-Hawa. In Christianity and Monasticism in Aswan and Nubia, The American University in Cairo Press, Cairo, 5, 117.

Fiorillo, F., Limongiello, M., Fernández-Palacios, B.J., 2016. Testing GoPro for 3D model reconstruction in narrow spaces. Acta IMEKO, 5(2), 64-70. 
Furukawa, Y., Hernández, C., 2015. Multi-view stereo: A tutorial. Foundations and Trends ${ }^{\circledR}$ in Computer Graphics and Vision, 9(1-2), 1-148.

Gabra, G., 2010. Coptic Monasteries: Egypt's Monastic Art and Architecture. The American University in Cairo Press, Cairo.

Grossmann, P., 1985. Ein neuer Achtstützenbau im Raum von Aswan in Oberägypten. In Mélanges Gamal Eddin Mokhtar. IFAO. Cairo, 339-348.

P. Grossmann, 1991. Dayr Qubbat al-Hawa: Architecture. In The Coptic Encyclopedia, vol. 3, Macmillan, New York, 851-852.

Koenderink, J.J., Van Doorn, A.J., 1991. Affine structure from motion. J Opt. Soc. Am. A, 8(2), 377-385.

Lowe, D.G., 2004. Distinctive image features from scaleinvariant keypoints. Int. J. Comput. Vision, 60(2), 91-110.

Ogleby, C.L., Papadaki, H., Robson, S., Shortis, M.R., 1999. Comparative camera calibrations of some "off the shelf" digital cameras suited to archaeological purposes. Int. Arch. Photogramm. Remote Sens. Spatial Inf. Sci., XXXII-5/W11, 6975 .

Martínez, S., Ortiz, J., Gil, M.L., Rego, M.T., 2013. Recording complex structures using close range photogrammetry: The cathedral of Santiago de Compostela. Photogramm. Rec., 28(144), 375-395.

Middleton-Jones, H., 2013. The Digital 3D Virtual Reconstruction of the Monastic Church, Qubbat al-Hawa. In Christianity and Monasticism in Aswan and Nubia, The American University in Cairo Press, Cairo, 5, 221

Mozas-Calvache, A.T., Pérez-García, J.L., Cardenal-Escarcena, F.J., Mata-Castro, E., Delgado-García, J., 2012a. Method for photogrammetric surveying of archaeological sites with light aerial platforms. J. Archaeol. Sci., 39(2), 521-530.

Mozas-Calvache, A.T., Pérez-García, J.L., Cardernal-Escarcena, F.J., Delgado, J., Mata de Castro, E., 2012b. Comparison of Low Altitude Photogrammetric Methods for Obtaining Dems and Orthoimages of Archaeological Sites. Int. Arch. Photogramm. Remote Sens. Spatial Inf. Sci., XXXIX-B5, 577-581.

Nex, F., Remondino, F., 2014. UAV for 3D mapping applications: a review. Appl. Geomatics, 6(1), 1-15.

Ortiz, J., Gil, M.L., Martínez, S., Rego, T., Meijide, G., 2013. Three-dimensional Modelling of Archaeological Sites Using Close-range Automatic Correlation Photogrammetry and Lowaltitude Imagery. Archaeol. Prospect., 20(3), 205-217.

Pérez-García, J.L., Mozas-Calvache, A.T., Gómez-López, J.M., Jiménez-Serrano, A., 2018. Three-dimensional modelling of large archaeological sites using images obtained from masts. Application to Qubbet el-Hawa site (Aswan, Egypt). Archaeol. Prospect. https://doi.org/10.1002/arp.1728

Scharstein, D., Szeliski, R., 2002. A taxonomy and evaluation of dense two-frame stereo correspondence algorithms. Int. J. Comput. Vision, 47(1-3), 7-42.

Seitz, S. M., Curless, B., Diebel, J., Scharstein, D., Szeliski, R., 2006. A comparison and evaluation of multi-view stereo reconstruction algorithms. In IEEE Computer Society Conference on Computer Vision and Pattern Recognition, IEEE, New York, USA, 519-528,

Szeliski, R., 2011. Computer Vision: Algorithms and Applications. Springer, London.

Ullman, S., 1979. The interpretation of structure from motion. Proc. Royal Soc. London B, 203, 405-426.

Verhoeven, G., Taelman, D., Vermeulen, F., 2012. Computer vision-based orthophoto mapping of complex archaeological sites: the ancient quarry of Pitaranha (Portugal-Spain). Archaeometry, 54(6), 1114-1129.

Waldhäusl, P., Ogleby, C.L., 1994. 3 x 3 rules for simple photogrammetric documentation of architecture. Int. Arch. Photogramm. Remote Sens., 30, 426-429.

Waldhäusl, P., Ogleby, C. L., Lerma, J. L., Georgopoulos, A., 2013. 3 × 3 rules for simple photogrammetric documentation of architecture. $\quad$ http://cipa.icomos.org/wpcontent/uploads/2017/02/CIPA_3x3 rules_20131018.pdf 